\title{
Predictive and Prognostic Factors in Breast Cancer and their Association with ER PR HER2/neu Expression
}

Sinha $\mathbf{S}^{1}$, Nath $\mathrm{J}^{1}$, Mukherjee $\mathrm{A}^{1}$ and Chatterjee $\mathrm{T}^{2^{*}}$

${ }^{1}$ Suraksha Diagnostic Centre, Salt Lake, Kolkata, West Bengal, India

2Suraksha Genomics, Salt Lake, Kolkata, West Bengal, India

"Corresponding author: Tridip Chatterjee, Suraksha Genomics (R \& D Division of Suraksha Diagnostic), DD-18/1. Sector 1, Salt Lake, Kolkata-700064, West Bengal, India, Tel: +91-033-6619-1000; E-mail: ctridip@gmail.com

Received date: April 02, 2016; Accepted date: April 27, 2016; Published date: April 29, 2016

Copyright: (C) 2016 Sinha S, et al. This is an open-access article distributed under the terms of the Creative Commons Attribution License, which permits unrestricted use, distribution, and reproduction in any medium, provided the original author and source are credited.

\section{Abstract}

Background: Breast Cancer is the most common malignancy amongst Indian women. Adjuvant therapy, which helps in prolonging survival, is determined by the expression of Estrogen Receptor (ER), Progesterone Receptor (PR) and Human Epidermal Receptor (HER2/neu) on the cancer cells. Expression of these receptors is governed by some patient and tumor characteristics.

Aims and objectives: The aim of this study is to look into the association of patient age, tumor grade and lymph node stage with ER PR HER2/neu expression.

Materials and methods: The study was conducted in the Department of Pathology of Suraksha Diagnostics for a period of two years (2014-2016). The sample size is 68. For all specimens of breast cancer received by modified radical mastectomy, patient age, tumor histological grade as per Nottingham's Histological score and lymph node stage were recorded and correlated with the ER, PR, HER2/ neu score for each specimen. ER positive tumors were considered to have favourable receptor expression while triple negative followed by ER negative tumors were considered to have unfavourable receptor expression.

Results and analysis: This study shows that breast cancers are more common in women aged more than 40 years $(73.5 \%)$ but younger women had more unfavourable receptor expression (61.1\%). Grade II tumors $(66.2 \%)$ were most common but Grade III tumors had more unfavourable receptor expression (90\%).N1 lymph node stage $(44.1 \%)$ was most common but N3 tumors had more unfavourable receptor expression (80\%).

Conclusion: Young age, higher tumor grade and higher lymph node stage are associated with more unfavourable receptor expression and adverse prognosis. Hence, early diagnosis of breast cancers will help detection at lower tumor grade and stage and improve patient survival.

Keywords: Estrogen receptor; Progesterone receptor; HER2/neu; Tumor gade; Lymph node stage

\section{Introduction}

There has been a rise in cancer cases among Indian women, with breast cancer being of particular concern. As per the statistics of 2015, the number of breast cancer cases were found to be 1,00,061 as against 94,208 cases of cervical cancer. Thus, breast cancer is now the most common malignancy among Indian women $[1,2]$.

Early diagnosis and appropriate treatment can prolong the survival of patients diagnosed with breast cancer. The normal treatment protocol is surgery followed by chemotherapy and radiotherapy, followed by adjuvant therapy. The kind of adjuvant therapy that can be given greatly influences survival and is determined by the expression of estrogen receptor (ER), Progesterone receptor (PR) and a transmembrane protein called HER2/neu expression on the cancer cells. ER / PR positive tumors are treated by Tamoxifen in pre-menopausal women and Aromatase inhibitors in post-menopausal women. HER2/neu positive tumors are treated by a monoclonal antibody known as Trastuzumab (Herceptin). No adjuvant therapy is available for ER/PR HER2/neu negative (triple negative) tumors $[3,4]$.

There are certain patient and tumor characteristics that affect ER, PR, HER2/neu expression on the tumor cells and thus helps in determining the adjuvant therapy and eventually the prognosis of breast cancer patients $[4,5]$.

The aim of this study is to find out the association of patient age, histologic grade and lymph node stage of tumor with ER, PR, HER2/neu expression on breast cancer cells and thereby identify them as important predictive and prognostic factors for breast cancer.

\section{Material and Methods}

The study was conducted for a period of two years, from 2014 to 2016, in the Department of Pathology, at Suraksha Diagnostic Centre, Kolkata, India.

Specimens of breast cancer from patients were received in our laboratory. Each specimen was accompanied by a test requisition form that contained detailed patient information including patient age, 
tumor laterality, site/quadrant of tumor involvement and the method of operation (Modified radical mastectomy/ Simple mastectomy/ Lumpectomy/ Trucut biopsy). Only specimens that were operated by modified radical mastectomy have been included in the study, else histologic grade of tumor and lymph node stage could not be determined. The sample size in this study is 68 .

The specimens were grossed as per standard protocols and sections were submitted for histopathological examination and stained by haematoxylin-eosin staining for microscopic examination.

The following tumor characteristics were noted on microscopic examination:

a) Histological type of tumor

b) Histological grade of tumor as per the Nottingham's histologic score

In this scoring system, there are three factors that are taken into consideration and each of these factors are scored from 1-3,

\section{The amount of gland formation or differentiation of the tumor}

Score 1: $>75 \%$ of tumor area forming glandular/tubular structures

Score 2: $10 \%$ to $75 \%$ of tumor area forming glandular/tubular structures

Score 3: $<10 \%$ of tumor area forming glandular/tubular structures

\section{The nuclear features or nuclear pleomorphism}

Score 1: Nuclei small with little increase in size in comparison with normal breast epithelial cells, regular outlines, uniform nuclear chromatin and little variation in size

Score 2: Cells larger than normal with open vesicular nuclei, visible nucleoli, and moderate variability in both size and shape

Score 3: Vesicular nuclei, often with prominent nucleoli, exhibiting marked variation in size and shape, occasionally with very large and bizarre forms.

The mitotic activity of the tumor (considering field diameter of microscope to be $0.58 \mathrm{~mm}$ and area to be 0.264 sq. $\mathrm{mm}$.)

Score 1: less than or equal to 9 mitoses per 10 high power fields

Score 2: 10-19 mitoses per 10 high power fields

Score 3: equal to or greater than 20 mitoses per 10 high power fields

Then each score is added to give a final total score ranging from 3-9. The final total score is used to determine the grade in the following way:

Grade 1 tumors have a score of 3-5

Grade 2 tumors have a score of 6-7

Grade 3 tumors have a score of 8-9

c) Presence of lymphovascular invasion and perineurial invasion

d) Presence of in situ component

e) Lymph node status of the tumor was determined in the following way
N0- No lymph nodes involved; N1-1 to 3 lymph nodes involved; N2- 4 to 9 lymph nodes involved; N3- 10 or more lymph nodes involved

f) Sections were also taken for immunohistochemical examination for study of ER, PR, HER2/neu status of the cancer specimens.

ER, PR scoring was done as per the Allred scoring system.

Allred scoring

Proportion score:

0 - No cells are ER positive

$1-\leq 1 \%$ of cells are ER positive

$2-1-10 \%$ of cells are ER positive

$3-11-33 \%$ of cells are ER positive

$4-34-66 \%$ of cells are ER positive

$5-67-100 \%$ of cells are ER positive

Intensity score:

0 - Negative

1 - Weak

2 - Intermediate

3 - Strong

ER/ PR status is considered negative when proportion score + intensity score is $\leq 2$ and positive when $\geq 2$.

HER2/neu scoring was done according to the standard reporting protocols (Table 1).

\begin{tabular}{|l|l|l|}
\hline $\begin{array}{l}\text { Score to } \\
\text { report }\end{array}$ & $\begin{array}{l}\text { HER2/neu protein } \\
\text { assessment }\end{array}$ & Staining pattern \\
\hline 0 & Negative & $\begin{array}{l}\text { No staining is seen or membrane } \\
\text { staining is seen in }<10 \% \text { of invasive } \\
\text { tumor cells }\end{array}$ \\
\hline $1+$ & Negative & $\begin{array}{l}\text { Faint/Barely perceptible membrane } \\
\text { staining detected in }>10 \% \text { of invasive } \\
\text { tumor cells }\end{array}$ \\
\hline $2+$ & $\begin{array}{l}\text { Weak to moderate complete } \\
\text { membrane staining in }>10 \% \text { of invasive } \\
\text { tumor cells }\end{array}$ \\
\hline $3+$ & Positive & $\begin{array}{l}\text { Strong complete membrane staining in } \\
>30 \% \text { of invasive tumor cells. }\end{array}$ \\
\hline
\end{tabular}

Table 1: HER2/neu report score Scale with Staining pattern and HER2/neu protein assessment.

A master chart was prepared and for each specimen, the following information were noted:

Patient age, histologic type of tumor, histologic score, tumor grade, number of lymph nodes involved, presence/absence of distant metastases, presence/absence of lymphovascular/perineurial invasion, presence/absence of in situ component, ER PR HER2/neu status of tumor.

Statistics show that ER + PR+/- HER2/neu +/- tumors have a good five year survival rate (about 94\%). As these tumors have good prognosis, these tumors are considered to have favourable hormone receptor expression [6-8].

Triple negative tumors followed by ER- PR+ HER2/neu - and ERPR- HER2/neu + tumors have a poor five year survival rate and a 
worse prognosis, and hence these are considered as unfavourable hormone receptor expression [6-8].

\section{Results and analysis}

In this short study period of two years, we studied 68 breast cancer specimens. We found that $26.5 \%$ of patients with breast cancer were less than or equal to 40 years of age while $73.5 \%$ of patients were above 40 years of age. Patients $\leq 40$ years of age had predominantly unfavourable hormone receptor status accounting for $61.1 \%$, while patients $>40$ years of age had predominantly favourable hormone receptor status: unfavourable hormone receptor status was seen in only $48 \%$ patients $>40$ years of age (Table 2 ).

\begin{tabular}{|l|l|l|}
\hline & $\begin{array}{l}\text { Unfavourable } \\
\text { (ER-PR-HER2-, ER- } \\
\text { PR+HER2-, ER-PR- } \\
\text { HER2+) }\end{array}$ & $\begin{array}{l}\text { Favourable } \\
\text { (ER+PR-HER2-, ER+PR- } \\
\text { HER2+, ER+PR+ } \\
\text { HER2-, ER+PR+HER2+) }\end{array}$ \\
\hline Age $\leq \mathbf{4 0}(\mathbf{n = 1 8})$ & 11 & 7 \\
\hline Age $>\mathbf{4 0}(\mathbf{n}=\mathbf{5 0})$ & 24 & 26 \\
\hline
\end{tabular}

Table 2: Association study of patient age with favourable/unfavourable hormone receptor status.

Of all the breast cancer specimens, 19.1\% were grade I, $66.2 \%$ were grade II and $14.7 \%$ were grade III tumors. $38.5 \%$ of Grade I, $51.1 \%$ of Grade II and $90 \%$ of Grade III tumors were associated with unfavourable hormone receptor status (Tables 3 and 4).

\begin{tabular}{|ll|l|l|}
\hline & $\begin{array}{l}\text { Unfavourable } \\
\text { (ER-PR-HER2-, ER- } \\
\text { PR+HER2-, ER-PR- } \\
\text { HER2+) }\end{array}$ & $\begin{array}{l}\text { Favourable } \\
\text { (ER+PR-HER2-, ER+PR-HER2+, } \\
\text { ER+PR+ } \\
\text { HER2-, ER+PR+HER2+) }\end{array}$ \\
\hline $\begin{array}{l}\text { Tumor } \\
\text { I(n=13) }\end{array}$ & Grade & 5 & 8 \\
\hline $\begin{array}{l}\text { Tumor } \\
\text { II }(\mathbf{n = 4 5 )}\end{array} \quad$ Grade & 23 & 22 \\
\hline $\begin{array}{l}\text { Tumor } \\
\text { III(n=10) }\end{array}$ & Grade & 9 & 1 \\
\hline
\end{tabular}

Table 3: Association study of tumor grade with favourable/ unfavourable hormone receptor status.

\begin{tabular}{|l|l|l|}
\hline & $\begin{array}{l}\text { Unfavourable } \\
\text { (ER-PR-HER2-, ER- } \\
\text { PR+HER2-, ER-PR- } \\
\text { HER2+) }\end{array}$ & $\begin{array}{l}\text { Favourable } \\
\text { ER+PR-HER2-, ER+PR-HER2+, ER } \\
\text { +PR+ } \\
\text { HER2-, ER+PR+HER2+) }\end{array}$ \\
\hline N0 $(\mathbf{n = 1 8 )}$ & 7 & 11 \\
\hline $\mathbf{N 1}(\mathbf{n = 3 0})$ & 12 & 18 \\
\hline $\mathbf{N} \mathbf{( n = 1 5 )}$ & 8 & 7 \\
\hline $\mathbf{N} 3 \mathbf{( n = 5 )}$ & 4 & 1 \\
\hline
\end{tabular}

Table 4: Association study of lymph node stage with favourable/ unfavourable hormone receptor status.
$26.5 \%$ of tumors belonged to N0 lymph node stage, $44.1 \%$ belonged to N1 lymph node stage, $22 \%$ were $\mathrm{N} 2$ and $7.3 \%$ were N3 tumors. The association of N0, N1, N2, N3 tumors with unfavourable hormone receptor status were found to be $38.9 \%, 40 \%, 53.3 \%$ and $80 \%$ respectively.

\section{Discussion}

Breast cancer, the most common malignancy in Indian women, has long-term disease free survival with the institution of timely and appropriate therapy. Adjuvant therapy, which is determined by the expression of ER PR HER2/neu on the breast cancer cells, is an important determinant of patient survival and prognosis following chemotherapy. Identification of factors that can affect the expression of these receptors may actually have a role in patient prognosis and is, therefore, essential.

This study with a small sample size of 68 has been able to make some important revelations.

Firstly, breast cancers are more common in the perimenopausal and post-menopausal age group i.e. in patients older than 40 years. However, young patients less than or equal to 40 years of age have more unfavourable hormone receptor status $(61.11 \%)$ in comparison to patients above 40 years of age(unfavourable hormone receptor status $=48 \%$ ). This observation is in concordance with other studies which state that breast cancers in young women have unfavourable biological behaviour and poor prognosis, than breast cancers in older women [8-10].

Secondly, the most common histological grade of the tumors in this study is Grade II (66.2\%). This means that most tumors are diagnosed when they progress to the histological grade of II. Thus it is necessary that women be educated about breast cancer, the importance of regular breast self-examination and urgent consultation of physician in case of development of any symptom. This will help in early diagnosis of breast cancer.

It was observed in this study that Grade III tumors, in $90 \%$ cases have unfavourable hormone receptor status, in contrast to Grade I and Grade II tumors which show association with unfavourable hormone receptor status in only $38.5 \%$ and $51.1 \%$ cases respectively. Thus, higher the tumor grade, more the unfavourable receptor expression and therefore, worse the prognosis. This is also in agreement with other studies which state that tumor histologic grade is an important determinant of hormone receptor status [11-15]. Tatjana IvkovićKapicl et al. in corroboration with our study, observed that highergrade tumors were more likely to demonstrate HER2/neu amplification than lower grade ductal carcinomas [16]. Similarly, other studies have also reported that histologic high-grade tumors are associated with an increased rate of HER2/neu positivity. HER2/neu was also found to correlate with high nuclear grade [17].

Thirdly, most tumors were diagnosed at the N1 lymph node stage. It was seen that $\mathrm{N} 3$ tumors have unfavourable hormone receptor status in $80 \%$ cases, which is much greater than N2, N1, N0 tumors $(53.3 \%$, $40 \%, 38.9 \%$ respectively). Thus, higher the lymph node stage, more the unfavourable receptor expression and poorer the prognosis. This observation also corroborates well with other studies which state that lymph node status is the single most important determinant which helps in deciding therapy [18-20]. Sepideh Siadati et al. in corroboration with our study, observed that HER2/neu expression significantly correlated with lymph node involvement [21]. As the 
number of positive axillary lymph nodes increases, survival rate decreases and relapse rate increases [22].

Statistical analysis was done with the Chi-Square test. A statistically significant association was observed between progressing tumor grade and unfavourable receptor expression with a p value of 0.036 . Due to the small sample size in this study, no statistically significant association could be obtained between age and lymph node stage, with receptor expression. However, from the differences in percentages, a definite trend is evident. Patients with age less than equal to 40 years have a $13.11 \%$ increased association with unfavourable receptor expression than for patients more than 40 years. Similarly, increasing association with unfavourable receptor expression was observed with progressing lymph node stage.

Small sample size is a limitation in this study. Despite that, from the Chi-square test and from the differences in percentages, tumor histological grade, patient age and lymph node stage can be identified as important predictive and prognostic factors for breast cancer.

\section{Conclusion}

This study, though done on a small sample size, has been able to draw important inferences. The study shows that breast cancer has a higher incidence in older women, but cancers in younger women of 40 years or less of age have more unfavourable hormone receptor expression and poor prognosis. The study also shows that higher grade tumors and tumors with higher lymph node stage have more unfavourable hormone receptor status.

A statistically significant association could be established between tumor grade and receptor expression. Hence, advancing tumor grade can be identified as a definite adverse prognostic factor for breast cancer. In absence of statistically significant association, but due to presence of a definite trend, patient age and lymph node stage can be identified as possible adverse risk factors for breast cancer.

Identification of these factors will eventually help in better treatment of breast cancers and improve patient survival.

However, as sample size is a limitation in this study, a larger study on a larger representative population would be necessary to draw statistically significant conclusions.

\section{Acknowledgment}

We duly acknowledge Suraksha Diagnostic Centre for providing us the infrastructural support to carry out the work at the laboratory.

\section{References}

1. Kamath R, Mahajan KS, Ashok L, Sanal TS (2013) A study on risk factors of breast cancer among patients attending the tertiary care hospital, in udupi district. Indian J Community Med 38: 95-99.

2. Khokhar A (2012) Breast cancer in India: where do we stand and where do we go? Asian Pac J Cancer Prev 13: 4861-4866.

3. Fadda GM, Santeufemia DA, Basso SM, Tozzoli R, Falcomer F, et al (2016) Adjuvant Treatment of Early Breast Cancer in the Elderly. Med Chem 12: 280-284.

4. Gupta D, Gupta V, Marwah N, Gill M, Gupta S, et al. (2015) Correlation of Hormone Receptor Expression with Histologic Parameters in Benign and Malignant Breast Tumors. Iranian Journal of Pathology 10: 23-34.
5. Dunnwald LK, Rossing MA, Li CI (2007) Hormone receptor status, tumor characteristics, and prognosis: a prospective cohort of breast cancer patients. Breast Cancer Res 9: R6.

6. Onitilo AA, Engel JM, Greenlee RT, Mukesh BN (2009) Breast Cancer Subtypes Based on ER/PR and Her2 Expression: Comparison of Clinicopathologic Features and Survival. Clin Med Res 7: 4-13.

7. Ren Z, Li Y, Shen T, Hameed O, Siegal GP, et al. (2016) Prognostic factors in advanced breast cancer: Race and receptor status are significant after development of metastasis. Pathol Res Pract 212: 24-30.

8. Sofi GN, Sofi JN, Nadeem R, Shiekh RY, Khan FA, et al. (2012) Estrogen receptor and progesterone receptor status in breast cancer in relation to age, histological grade, size of lesion and lymph node involvement. Asian Pac J Cancer Prev 13: 5047-5052.

9. Thangjam S, Laishram RS, Debnath K (2014) Breast carcinoma in young females below the age of 40 years: A histopathological perspective. South Asian J Cancer 3: 97-100.

10. Maggard MA, O'Connell JB, Lane KE, Liu JH, Etzioni DA, et al. (2003) Do young breast cancer patients have worse outcomes? J Surg Res 113: 109-113.

11. Rao C, Shetty J, Kishan Prasad HL (2013) Morphological profile and receptor status in breast carcinoma: an institutional study. J Cancer Res Ther 9: 44-49.

12. Zhu X, Ying J, Wang F, Wang J, Yang H (2014) Estrogen receptor, progesterone receptor, and human epidermal growth factor receptor 2 status in invasive breast cancer: a 3,198 cases study at National Cancer Center, China. Breast Cancer Res Treat 147: 551-555.

13. Elston CW, Ellis IO (1991) Pathological prognostic factors in breast cancer. I. The value of histological grade in breast cancer: experience from large study with long-term follow-up. Histopathology 19: 403-410.

14. Pinder SE, Murray S, Ellis IO, Trihia H, Elston CW, et al. (1998) The importance of the histologic grade of invasive breast carcinoma and response to chemotherapy. Cancer 83: 1529-1539.

15. Shokouh TZ, Ezatollah A, Barand P (2015) Interrelationships Between Ki67, HER2/neu, p53, ER, and PR Status and Their Associations With Tumor Grade and Lymph Node Involvement in Breast Carcinoma Subtypes: Retrospective-Observational Analytical Study. Medicine 94: e1359.

16. Ivkovic-Kapicl T, Knezevic-Usaj S, Djilas-Ivanovic D, Panjkovic M (2007) Correlation of Her-2/neu protein overexpression with other prognostic and predictive factors in invasive ductal breast cancer. In Vivo 21: 637-678.

17. Hoff ER, Tubbs RR, Myles JL, Procop GW (2002) HER2/neu amplification in breast cancer: stratification by tumor type and grade. Am J Clin Pathol 117: 916-921.

18. Azizun-Nisa, Bhurgri Y, Raza F, Kayani N (2008) Comparison of ER, PR and HER-2/neu (C-erb B 2) reactivity pattern with histologic grade, tumor size and lymph node status in breast cancer. Asian Pac J Cancer Prev 9: 553-556.

19. Mahmood H, Faheem M, Mahmood S, Sadiq M, Irfan J (2015) Impact of age, tumor size, lymph node metastasis, stage, receptor status and menopausal status on overall survival of breast cancer patients in Pakistan. Asian Pac J Cancer Prev 16: 1019-1024.

20. Payne SJ, Bowen RL, Jones JL, Wells CA (2008) Predictive markers in breast cancer--the present. Histopathology 52: 82-90.

21. Siadati S, Sharbatdaran M, Nikbakhsh N, Ghaemian N (2015) Correlation of ER, PR and HER-2/Neu with other Prognostic Factors in Infiltrating Ductal Carcinoma of Breast. Iran J Pathol 10: 221-226.

22. Tokatli F, Altaner S, Uzal C, Ture M, Kocak Z, et al. (2005) Association of HER-2/neu overexpression with the number of involved axillary lymph nodes in hormone receptor positive breast cancer patients. Exp Oncol 27: 145-149. 